(C2007 IEEE. Personal use of this material is permitted. However, permission to reprint/republish this material for advertising or promotional purposes or for creating new collective works for resale or redistribution to servers or lists, or to reuse any copyrighted component of this work in other works must be obtained from the IEEE. 


\title{
IMPROVED FAULT-RIDE-THROUGH CAPABILITY OF GRID CONNECTED WIND TURBINE DRIVEN DFIG
}

\author{
H. N. D. Le, Student, and S. Islam, Senior Member, IEEE
}

\begin{abstract}
This paper discusses dynamic model of DFIG wind generator and improvement of controllers for better interaction between wind farm and power system during transient grid fault events. The improvements include Controller Implementation of Blade Pitch Angle, Frequency Stabilizer, Drive Train Stabilizer and STATCOM operation of the Grid Side Converter.
\end{abstract}

Index Terms-doubly fed induction generator, drive train stabilizer, DIgSILENT Power Factory, fault ride through, rotor side converter, grid side converter, Park's transformation, pitch control, power system stabilizer, STATCOM.

\section{INTRODUCTION}

$\mathrm{T}$ HERE is a significant push to increase renewable energy penetration into our grid. Among various options, wind energy is considered to be the most promising candidate to provide electrical energy in years to come. Up to this moment, the total wind power generation only covers a small fraction of total power system loads. However, a tendency to increase the amount of electricity generated from wind is easily observed. When the wind power generation increases, they begin to influence overall power system behavior. As a result, the influence of the wind farms on grid stability and their control capabilities are required to be investigated.

In addition to this, to be able to be a substantial part of power system and replace the conventional power plant, wind turbines have to contribute to power system control and full fill the stabilization tasks. One of these control tasks is to deal with the transient disturbance in power system including voltage and frequency excursions. The wind turbines have to be able to ride through transient system fault, contribute to voltage recovery, frequency stabilization and damping of torsional drive train oscillations. These problems will be addressed in this paper and are limited to DFIG generator only.

Presented results are based on simulations in the power system simulation tool DIgSILENT Power Factory. The model is built on the existing standard DFIG model in Power Factory. The wind turbine controllers and control strategies are developed to enable better performance of DFIG in riding through transient fault and power system stabilization. A test case is also investigated to simulate different transient fault situations and assessing the interactions between power system and wind turbine.

\section{II.BACKGROUND}

\section{A. Park's Transformation:}

For controller algorithm simplification, the machine quantities should be expressed on d-q reference frame by employing Park's transformation. The $\mathrm{d}-\mathrm{q}$ reference frame is one with the axes rotating at speed $\omega_{\text {rot }}$. The q-axis is assumed to be $90^{\circ}$ ahead of the d-axis in the direction of rotation. If the d-axis is so chosen that it coincides with the phase a axis at time $\mathrm{t}=0\left(\theta_{\text {rot.initial }}=0^{0}\right)$, its displacement from phase a axis at any time $\mathrm{t}$ is $\omega_{\text {rot }} t$. Assuming balance voltage and non ground connection point (zero sequence free quantities), the transformation of abc phase variables to $d-q$ variables can be written in the following matrix form:

$$
\left[\begin{array}{l}
i_{d} \\
i_{q}
\end{array}\right]=\frac{2}{3}\left[\begin{array}{ccc}
\cos \theta_{r o t} & \cos \left(\theta_{r o t}-\frac{2 \pi}{3}\right) & \cos \left(\theta_{r o t}+\frac{2 \pi}{3}\right) \\
-\sin \theta_{r o t} & -\sin \left(\theta_{r o t}-\frac{2 \pi}{3}\right) & -\sin \left(\theta_{r o t}+\frac{2 \pi}{3}\right)
\end{array}\right]\left[\begin{array}{c}
i_{a} \\
i_{b} \\
i_{c}
\end{array}\right](2.1)
$$

where, $i_{d, q}=$ current quantities on $\mathrm{d}$ and q axis, respectively.

$$
i_{a, b, c}=\text { phase A,B,C current }
$$$$
\theta_{\text {rot }}=\omega_{\text {rot }} t+\theta_{\text {rot.initial }} \text { : angle displacement of rotating }
$$
reference frame at time t.

By choosing the rotational speed $\omega_{\text {rot }}$ and initial angle $\theta_{\text {rot.initial }}$, system variables can be freely expressed in any reference frame.

Assuming the phase voltage is constant, if the d-axis is aligned to the phase voltage at time $\mathrm{t}=0$, the current on $\mathrm{d}$-axis represents for the projector of current vector on voltage axis. Therefore, controlling d-axis current directly relates to active power control. On the other hand, because the q-axis is perpendicular to d-axis, 
the reactive power has straight relationship to q-axis current and is controlled by this quantity.

An alternative method is expressing the machine quantities on the flux oriented reference frame. On flux oriented reference frame, the $\mathrm{d}$-axis is collinear to maximum flux vector. If the machine winding resistance is neglected, the flux vector is perpendicular to voltage vector. Consequently, the reactive power is controlled by d-axis current when active power is dominated by q-axis current quantity.

The d-q decomposition allows decoupling of active and reactive power control.

\section{B. DFIG Concept:}

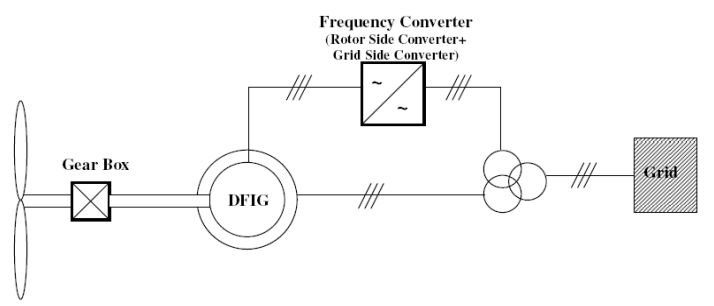

Figure 2.1 Variable speed doubly fed induction generator

Figure 2.1 shows a basic configuration of Doubly Fed Induction Generator (DFIG) concept. The DFIG consists of a Wound Rotor Induction Generator with the stator windings directly connected to the constant-frequency three-phase grid and with the rotor windings mounted to a frequency converter. The frequency converter is a bidirectional back-to-back voltage source converter which is partially rated at approximately $30 \%$ of the nominal generator power. This configuration allows wind system exchange power to the grid through both stator and rotor. In addition to this, the frequency converter operation allows the rotor speed varies around the synchronous speed in a certain range depending on the converter rating. Variable speed wind generator provides maximum power point tracking capability and therefore improves total energy production.

\section{DFIG Generator and Rotor Side Converter:}

In DIgSILENT Power Factory, the DFIG model is provided as a black box which contains model of circuit in figure 2.2

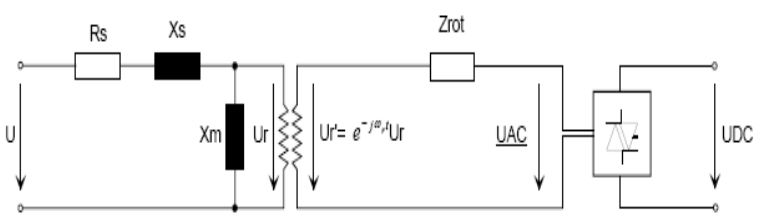

Figure 2.2 DFIG with rotor side converter
Basically, the model equations of the doubly fed machine are similar to normal induction machine with additional rotor voltage component $\underline{u}_{R}$ in rotor voltage equations:

$$
\begin{aligned}
& \underline{u}_{s}=R_{s} i_{s}+\frac{d \underline{\psi}_{s}}{\omega_{n} d t}+j \frac{\omega_{s y n}}{\omega_{n}} \underline{\psi}_{s} \\
& \underline{u}_{r} e^{j\left(\omega_{r}-\omega_{s y n}\right) t}=R_{r} \underline{i}_{r}+\frac{d \underline{\psi}_{r}}{\omega_{n} d t}+j \frac{\omega_{s y n}-\omega_{r}}{\omega_{n}} \underline{\psi}_{r}
\end{aligned}
$$

The per unit rotor voltage that appears in the above equation is divided to $\mathrm{d}$ and $\mathrm{q}$ components and related to the DC-voltage as follows:

$$
\begin{aligned}
& \underline{u}_{r d}=\frac{\sqrt{3}}{2 \sqrt{2}} P W M_{d} \frac{U_{D C}}{U_{r n o m}} \\
& \underline{u}_{r q}=\frac{\sqrt{3}}{2 \sqrt{2}} P W M_{q} \frac{U_{D C}}{U_{r n o m}}
\end{aligned}
$$

where, $\underline{u}_{s}, \underline{u}_{r}=$ per unit stator and rotor voltage

$\underline{\psi}_{s}, \underline{\psi}_{r}=$ per unit flux of stator and rotor

$\omega_{n}=2 \pi f_{n}$ where $f_{n}$ is the nominal frequency of the network

$\omega_{\text {syn }}=$ synchronous angular speed

$\omega_{r}=$ rotor angular speed

$P W M_{d}, P W M_{q}=\mathrm{d}$ and $\mathrm{q}$ modulation factor of rotor side converter

$U_{\text {rnom }}=$ nominal rotor voltage

$U_{D C}=\mathrm{dc}$ link voltage

\section{PWM Converter Model}

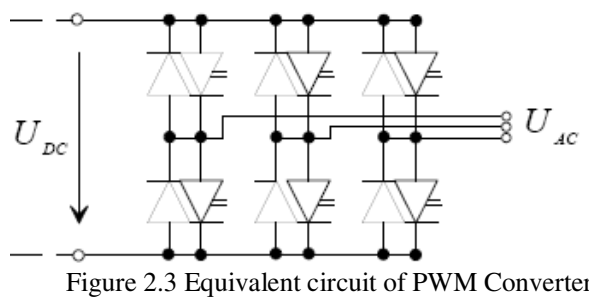

The PWM converter model represents a self-commutated, voltage sourced AC/DC converter. In figure 2.3, the fundamental frequency, the ideal, loss-less converter can be modeled by a DC-voltage controlled AC-voltage source conserving active power between AC- and DC-side. Assuming an ideal DCvoltage and an ideal PWM modulation (infinite modulation frequency), the fundamental frequency line to line $\mathrm{AC}$ voltage (rms value) and the DC voltage can be related to each other as follows: 


$$
\left|U_{A C}\right|=\frac{\sqrt{3}}{2 \sqrt{2}} P W M_{m} U_{D C} \text { for } 0 \leq P W M_{m} \leq 1
$$

Mohan [6] pointed out that equation 2.4 is valid only for linear modulation with $P W M_{m} \leq 1$. For $P W M_{m}>1$, the converter enters saturating and the level of low order harmonics starts increasing. Therefore, DFIG operation range is restricted within linear modulation $\left(0<P W M_{m} \leq 1\right)$. This constraint results in the dc link voltage is boosted to a level higher than the amplitude of the ac line-to-line voltage and the harmonic amplitude is minimized [6].

Equation 2.4 can be described on d-q reference frame on the similar way to equation 2.3. The model of PWM converter ends up with open loop d-q voltage controller. Because PWM converter employs high speed power electronic devices, a fast current control loop can be added, and the voltage controlled voltage source can be considered as current controlled voltage source. The current control loop employs two fast PI controllers as shown in figure 2.4:
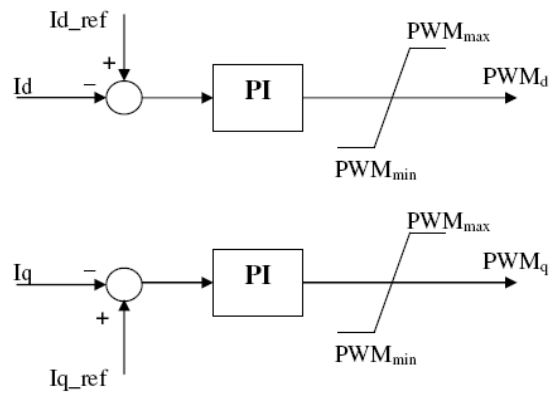

Figure 2.4 Additional Fast Current Controller of PWM Converter

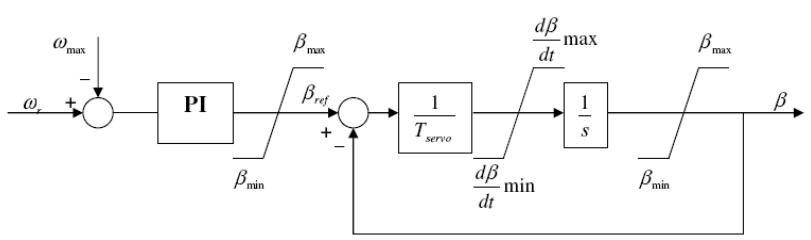

Figure 2.5 Block Diagram of Pitch Controller

\section{E. Pitch Angle Control:}

Controller and servomechanism of Pitch Angle Control are depicted in Figure 2.5. The controller has a feedback of the generator speed. Its speed-reference is set to the maximum speed which depends on the size of frequency converter. The blade angle is at the minimum limit of the controller for all operating conditions below rated rotor speed. This minimum limit corresponds to the optimum blade angle.
The servomechanism model accounts for the associated time constant $T_{\text {servo }}$, rate-of-change limits $\left(\frac{d \beta}{d t} \min , \max \right)$ and blade angle limitations $\beta_{\min , \max }$.

\section{F. Converter protection:}

The excitation of DFIG is organized with the use of the partial-load frequency converter which is fast-response but very sensitive to overload condition. In addition to this, the frequency converter is rated much smaller than the generator (normally $30 \%$ of DFIG size), therefore, the frequency converter protection must be modeled with its controller. When transient fault occurs, the collapsed voltage at wind turbine terminal causes high current in electronic device and voltage excursion at DC link capacitor. If the current, voltage or fault duration exceeds limitation, the crow-bar protection will be triggered to prevent converter damage.

Basic operation of crow-bar protection is that the rotor side converter is blocked and disconnected from rotor, while rotor is short circuited by impedance $[1,2]$.Therefore, DFIG will act as a normal induction generator with extra impedance at rotor side during converter blocking. Crow-bar protection causes the reduction of rotor current, which also reduces rotor flux, and in turn, the reactive power consumption of DFIG during converter blocking. When the grid voltage is recovered, the rotor side converter start synchronizing with rotor, disconnecting crow-bar and taking back the power control task. By using this method, during transient fault, besides converter protection issue, the DFIG puts less stress on reactive power demand, improves voltage recovery performance when it still maintains grid connection.

\section{G. DFIG Control:}

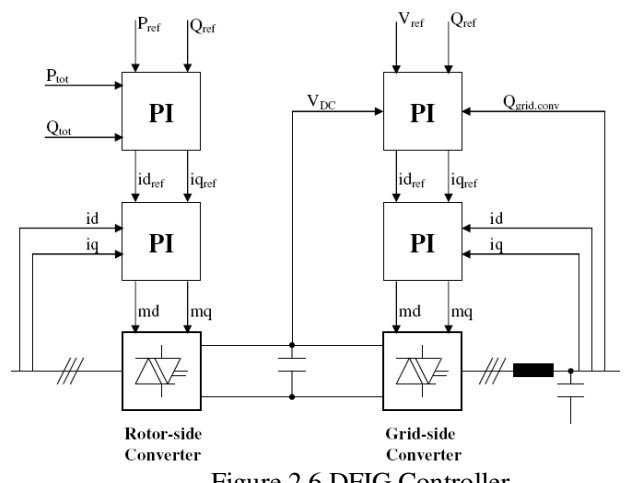

In normal operation, DFIG controller includes the rotor side converter and grid side converter controller. The rotor side converter organizes the total active power output according to 
Maximum Power Tracking when keeping whole system at unity power factor (zero total reactive power). On stator flux oriented reference frame, the total active and reactive power can be controlled by organizing rotor current $i_{q r}$ and $i_{d r}$ respectively. The rotor current on d-axis and q-axis are able to be controlled by regulating complex modulation factor of rotor side converter. To achieve the controllability of the rotor side converter, the dclink voltage needs to be kept at constant value.

The grid side converter is used mainly for keeping dc link voltage constant. Assuming lossless converter and dc capacitor, this means that the grid side converter must supply exactly the rotor converter active power requirement for sub-synchronous mode, or must transfer to grid exactly the same active power produced from rotor converter in super-synchronous mode. Active power regulation is the main point of dc link voltage regulation and this is done by controlling the d-axis current on stator voltage oriented reference frame. On the other hand, the reactive power of grid converter depends on q-axis current and this parameter is free-controlled and does not depend on rotor side converter operation.

Strictly speaking, the main role of grid side converter is active power supporter for rotor side converter during normal operation. The reactive power is considered not important and converter works at unity power factor to be able to give all its capacity for active power regulation. However, in some case, the grid side converter is set to produce a small amount of reactive power for compensating the reactive power demand of line impedance and transformer winding at connection point.

\section{III.FAULT RIDE THROUGH CAPABILITY IMPROVEMENT}

The improvement of DFIG controller will be discussed in the following order:

- The rate of pitch angle change is usually designed at a slow value (around $10 \%$ s) to prevent excursion of wind speed on the WT blades, therefore the reaction of pitch controller is very slow in case of transient fault, when the mechanical power output should be reduced as fast as possible to prevent the speed acceleration. As a result, an additional fault controller will be added to improve the blade speed during and after transient fault.

- If the fault is far away from the WTG terminal, the grid side converter acts as a power stabilizer to contribute damping to the stator power oscillation. However, the grid side converter is not able to effectively damp the rotor speed oscillation, especially in the case that the fault occurs close to WTG terminal. The high oscillation of the rotor speed causes high stress on mechanical coupling leads to system failure. In addition to this, large rotor speed excursion results in pitch controller, which is relatively slow, must work very hard to reduce the mechanical power input from wind. Therefore Drive Train Stabilizer (DTS) should be design to improve system performance.

- With P-Q controller implemented at rotor side converter, DFIG is able to satisfy the required active and reactive power from the utility regulator. However, when the wind turbine capacity become significant in total power system capacity, the requirement of frequency stabilizer or Power System Stabilizer (PSS) is extremely necessary.

- During the transient fault that makes converter disconnected from rotor, keeping grid side converter working at unity power factor means wasting the converter capability when grid is demanding reactive power. STATCOM operation of grid side converter during transient fault is able to support reactive power to the grid and therefore grid voltage can be recovered faster.

\section{A. Fault Controller Implementation in Blade Angle Control:}

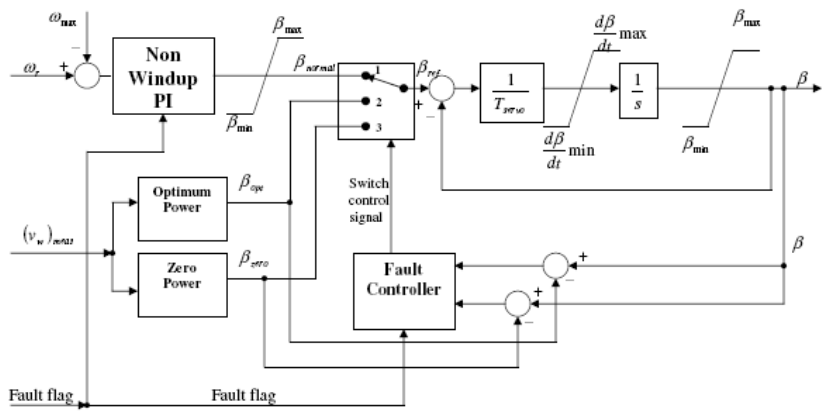

Figure 3.1 Integration of Fault Controller.

In figure 3.1, the Blade Control System is modified for better fault ride through capability. The Max Power Block and Zero Power Block store the pitch angle values corresponding to maximum and zero power output, respectively, over the whole range of wind speed. The Fault Controller controls the reference pitch angle input to the servo following a riding through strategy. The non windup PI Controller is used instead of normal PI controller to stop the accumulation of integrator during the time that switch position is at 2 or 3 .

In normal operation, the Blade Angle Control is regulated by normal PI pitch controller (switch position at 1). When the fault occurs close to wind generator terminal, fault flag from Protection Block will trigger the Fault Controller. Basic operation of Fault Controller can be explained as follows:

- The Fault Controller takes over from servo control. It increases the pitch angle with maximum rate to desired value which get reference from Zero Power Block (switch position is at 3 ). 
- After transient fault, when the grid voltage is recovered, the fault controller regulates the pitch angle back to optimum value which is referenced from Optimum Power Block, at maximum pitch rate (switch position at 2)

- When the pitch angle reaches the optimum value, the fault controller will hand over Blade Control to Normal operation (switch position goes back to 1)

There is a restriction of power ramp rate after the fault in some Grid Requirement Regulation such as in [4]. However, if wind farm has responsibility of frequency regulation, the pitch angle should go back to optimum value as fast as possible and WT has full capacity to be able to regulate system frequency. On the other hand, DFIG is equipped with power electronic controller that has very fast response compare to mechanical controller. Therefore, preventing speed excursion or required power ramp rates is quickly achieved by the power electronic controller.

\section{B. Power System Stabilizer (Frequency Stabilizer)}

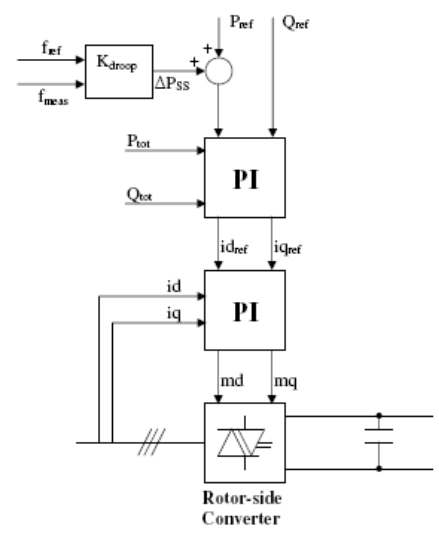

Figure 3.2 Integration of Power System Stabilizer(PSS)

The measured value of frequency $f_{\text {meas }}$ is compared to reference frequency $f_{\text {ref }}$. If $f_{\text {meas }}$ is less than $f_{\text {ref }}$, the Power System Stabilizer (PSS) will add an positive amount of $\Delta P_{s s}$ to order DFIG pumping more power, and vice versa. The $\Delta P_{s s}$ is calculated as following:

$$
\Delta P_{s s}=K_{\text {droop }}\left(f_{\text {meas }}-f_{\text {ref }}\right)
$$

where $K_{\text {droop }}$ is the drooping factor, which determines the percentage of frequency deviation will cause $100 \%$ change in DFIG power output [5].

\section{Drive Train Stabilizer}

After fault is cleared, rotor speed oscillates, if the rotor speed swings to a higher steady state value, that means extra rotation energy is stored in the lumped inertia of rotor and wind turbine, and if the rotor speed falls below steady state value, rotation energy is extracted from lumped inertia. The basic idea of DTS is when the speed oscillates above steady state value, DFIG is ordered to inject more power to the grid to prevent speed acceleration, further more, when the speed oscillates lower than steady state value; the DFIG is ordered to inject less power to prevent further deceleration of rotor speed. The block DTS take the measurement value of rotor speed $\omega_{\text {meas }}$ and compare it with reference value $\omega_{\text {ref }}$. Any difference between these two values will result in additional power $\Delta P_{D T S} \propto \operatorname{sign}\left(\omega_{\text {meas }}-\omega_{\text {ref }}\right)\left(\omega_{\text {ref }}-\omega_{\text {meas }}\right)^{2} J_{\text {lumped }}$ where $J_{\text {lumped }}$ is the equivalent of rotor and wind turbine inertia

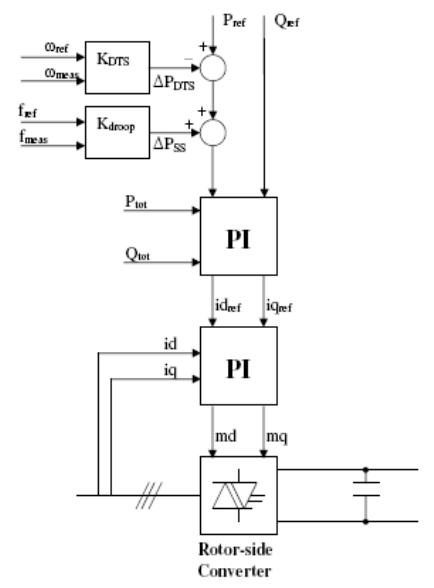

Figure 3.3 Integration of Drive Train Stabilizer(DTS)

\section{STATCOM Operation of Grid Side Converter:}

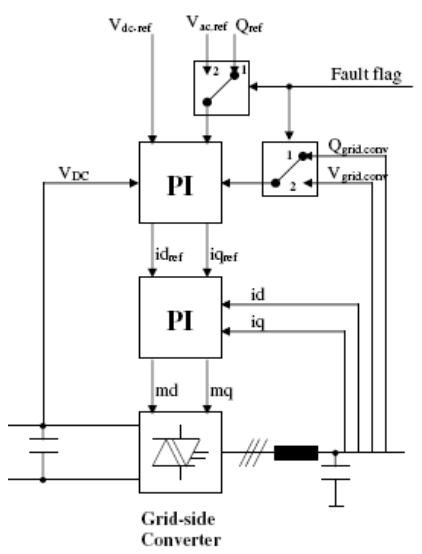

Figure 3.4 Grid Side Converter Control with Additional STATCOM Function During Transient Fault.

During normal operation, the grid side converter is an active power supporter of the rotor side converter. The reactive power of GSC is considered not important and converter works at unity 
power factor to be able to give all its capacity for active power regulation (both switches are at position 1 ).

During transient fault, the rotor side converter is disconnected from rotor circuit, the crowbar protection and additional rotor impedance reduces significantly the reactive power of DFIG. When the fault has just been cleared, the rotor converter starts synchronization (crow bar has not been removed during synchronization of rotor converter), DFIG (acting as induction generator) will withdraw larger amount of reactive power and have negative impacts on power system voltage recovery. During this time, the grid side converter should acts as STATCOM device to pump as much reactive power as possible to recover voltage at terminal point. Therefore, the grid side converter is switched from zero reactive power mode to voltage control mode (switches are at position 2).

\section{RESULTS AND DISCUSSIONS}

The performance of the controller is tested step by step with a given Test Case in Appendix A. Assuming that before fault occurs; system is operating at rated wind speed and maximum power is extracted. In addition to this, the reactive power set point is zero at PCC $66 \mathrm{kV}$ (this means that DFIG produce a little reactive power to compensate reactive power demand of transformer).

\section{A. Fault Controller Implementation in Blade Pitch Angle Control:}

(a)

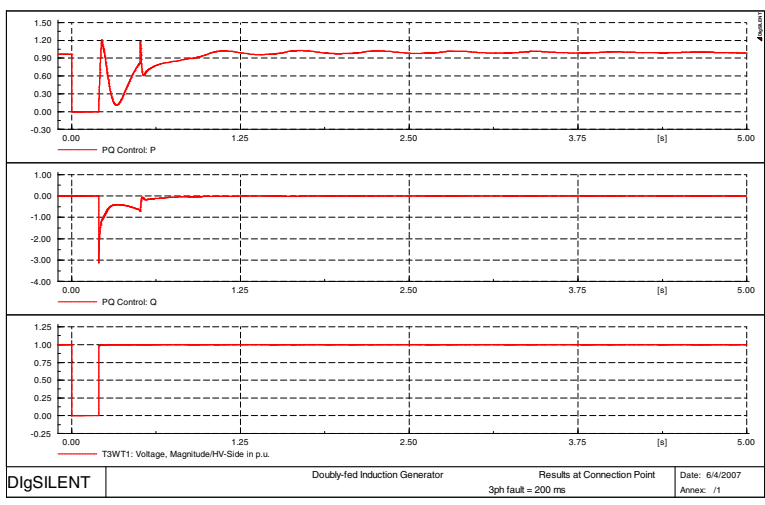

Figure 4.1: Connection Point Results (a)

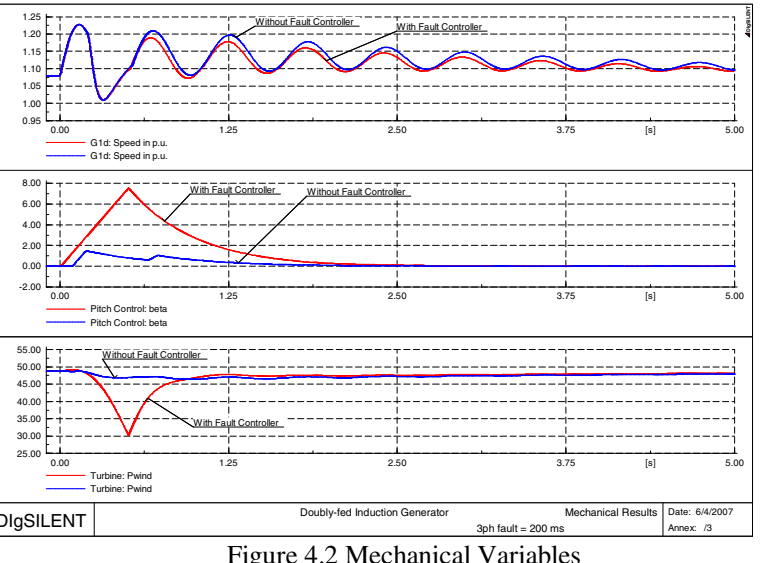

In this case, a three phase fault cleared after 200 ms causing a total voltage depression at the HV side of the machine transformer is simulated. The results are presented in figure 4.1 and figure 4.2 .

The three phase fault in this case causes the crowbar protection tripped. In figure 4.1 which shows power and voltage at connection point, there is evidence of full recovery of power and voltage.

As illustrated in figure 4.2(b), the Blade Angle Control equipped with fault controller effectively regulates the pitch angle to higher value than the basic Blade Angle Control. This results in significant reduction in extracted wind power (figure 4.2(c)). The less unbalance between mechanical power and electrical output will result low magnitude of speed oscillation as illustrated in figure 4.2(a).

The modified Blade Angle Control results in better damping of rotor speed after transient fault.

\section{B. Power System Stabilizer (Frequency Stabilizer):}

In this case, a three phase fault cleared after $200 \mathrm{~ms}$ causing a total voltage collapse at ST1 $110 \mathrm{kV}$ (Wind Farm terminal) is simulated. The results are presented in figures 4.6 to 4.7 .

(a)

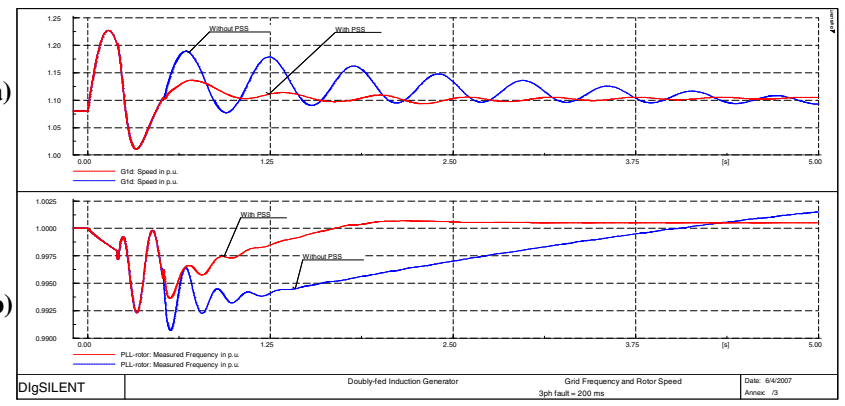

Figure 4.3 Rotor Speed of DFIG and Grid Frequency at DFIG terminal 
From figure 4.3(b), it can be seen that the frequency of system that is equipped with PSS quickly entered steady state value when without-PSS-system frequency kept accelerating. In addition to this, the rotor speed oscillation is effectively damped by PSS operation. Without PSS, the rotor inertia is almost decoupled from grid because rotor speed is controlled by rotor side converter. With PSS implementation, the rotor inertia is added to the total system inertia; therefore, the inertia of other machine will create a torque that is against the DFIG rotor oscillation and provide sufficient damping. In other words, the PSS creates an additional electrical torque that is in phase with rotor speed oscillation and provides effective damping.

(a)

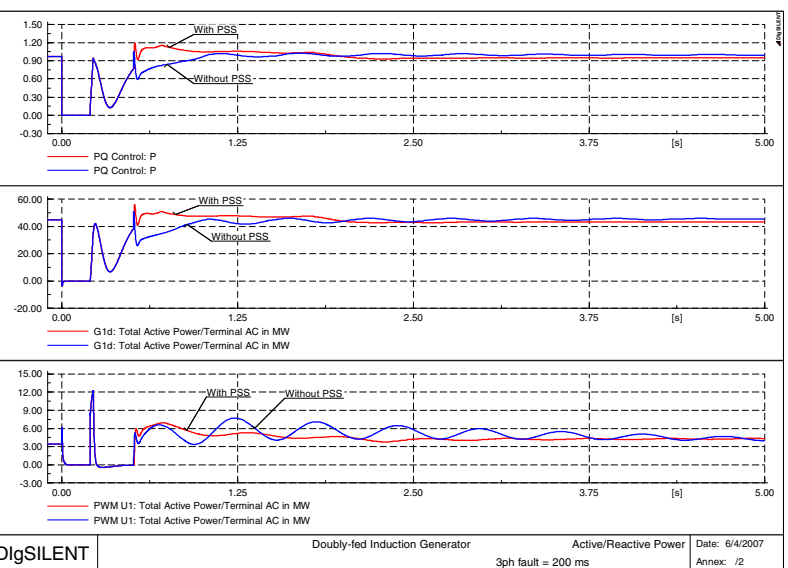

Figure 4.4 (a)Total DFIG Active Power Output; (b) Stator Active Power Output; (c) Grid Side Converter Active Power

Figure 4.4(a) and (b) demonstrates the effect of PSS on total DFIG power and stator output of DFIG. After the fault is cleared and crow bar protection is disabled, the active power of stator in case of PSS is much smoother than the case without PSS. In addition to this, the PSS also results in smooth working of the grid side converter (figure 4.4(c))

\section{Drive Train Stabilizer}

In this case, a three phase fault cleared after $400 \mathrm{~ms}$ causing a total voltage collapse at ST1 $110 \mathrm{kV}$ (Wind Farm terminal) is simulated. The results are presented in figure 4.5 . The rotor speed with DTS system completely damped the speed oscillation after 2.4 secs compared to the system without DTS, the speed oscillation is completely damped after $5 \mathrm{secs}$. Note that, because the PSS also has damped the rotor speed very well, the outcome of DTS $\Delta P_{D T S}$ is small compared to PSS output $\Delta P_{s S}$ and does not affect on the frequency regulation of PSS. As seen in figure 4.5(b), the frequency of both cases, with and without DTS reached the steady state at the same time. Further more, the active power of DFIG are similar in both cases (figure 4.6). This result consolidates the conclusion that the DTS also supports PSS for rotor speed stabilization. (a)

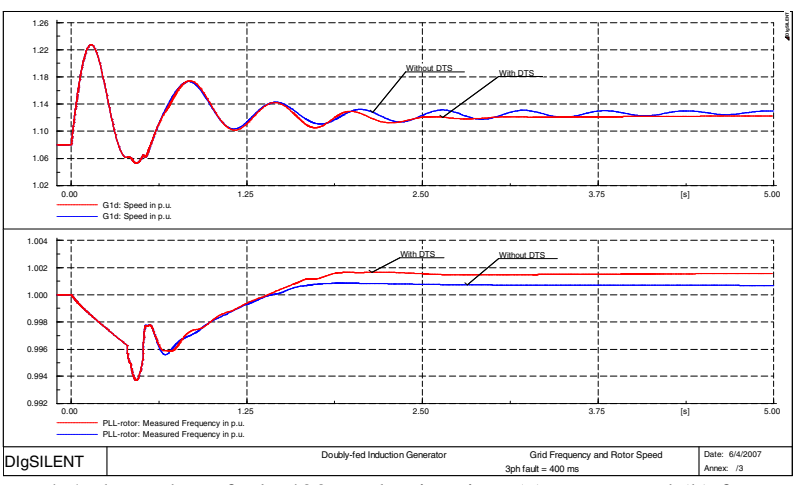

Figure 4.5 Three phase fault, $400 \mathrm{~ms}$ clearing time;(a) rotor speed;(b) frequency at wind Farm Terminal

(a)

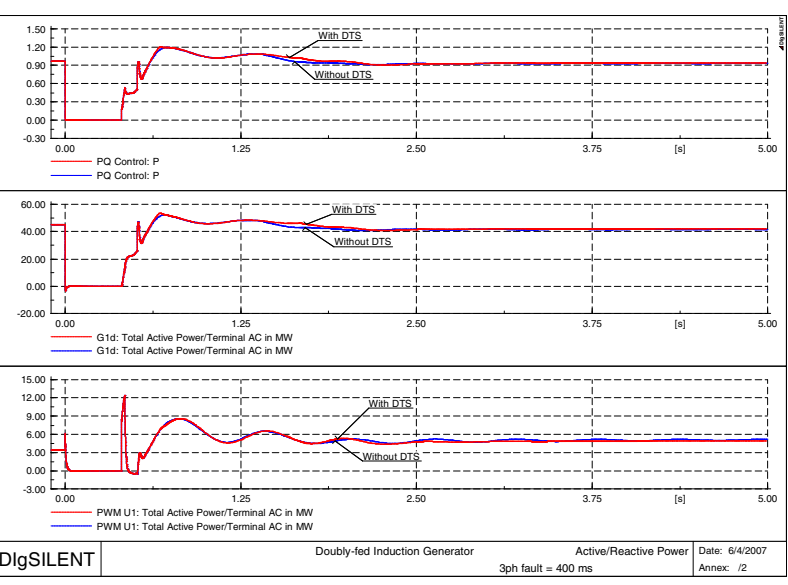

Figure 4.6 Three phase fault, 400ms clearing time; (a) Active Power at HV of Transformer; (b) Stator Active Power; (c) Grid Side Converter Active Power

\section{STATCOM Operation of Grid Side Converter(GSC)}

In this case, a three phase fault cleared after $200 \mathrm{~ms}$ causing a voltage dip of about $60 \%$ at wind turbine terminal is simulated. Assuming that the under-voltage protection is disabled to avoid the disconnection from the grid under these circumstances, following result is obtained:

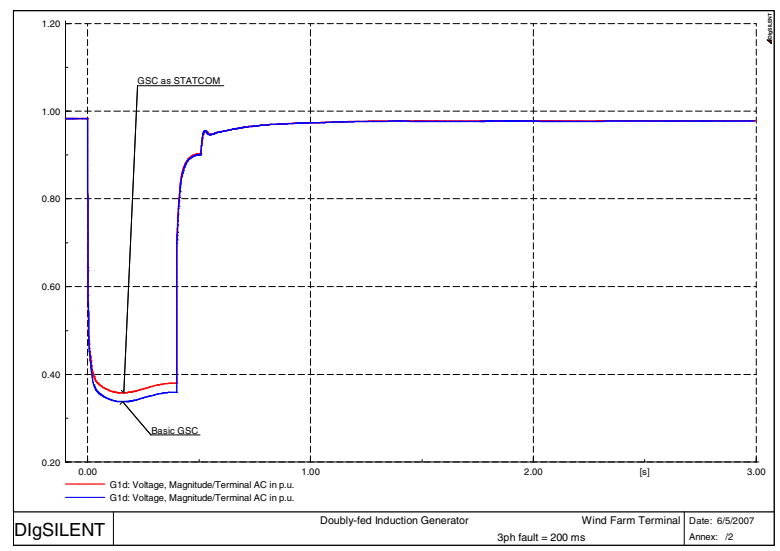

Figure 4.7 Voltage at Wind Farm Terminal. 
Figure 4.7 shows the voltage improvement when grid side converter (GSC) is controlled as STATCOM device during transient fault. Although the voltage improvement is not one hundred percent, it is significant due to small size of the DFIG converter. The use of GSC for voltage improvement together with a well designed controller exploits all capability of DFIG to remain connected and support voltage recovery during transient faults.

(a)

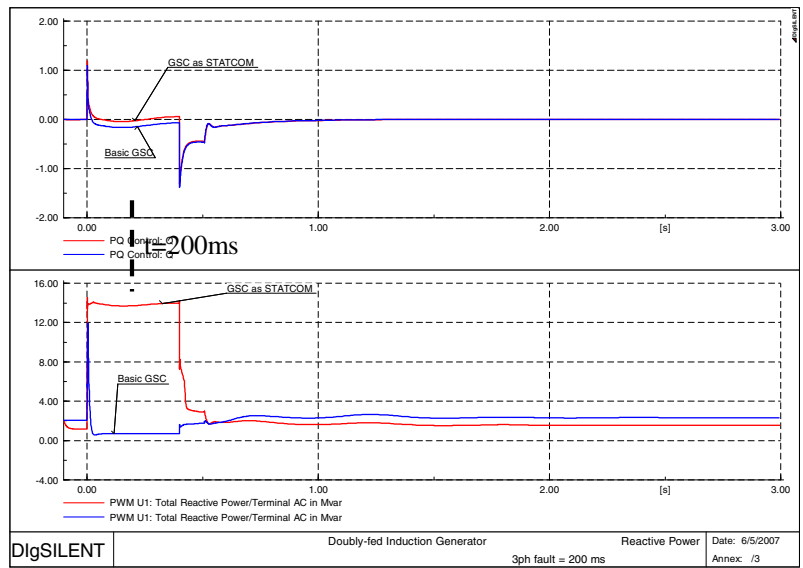

Figure 4.8 Reactive Power of (a) Wind Farm Terminal (b) Grid Side Converter

Figure 4.8 (a) and (b) show the reactive power output of a wind farm and GSC. Figure 4.8(b) shows the huge difference of reactive power output of GSC when it acts as a STATCOM. This results in approximately zero reactive power consumption of DFIG during the fault (from $t=0$ to $t=200 \mathrm{~ms}$ ). When the fault is cleared and the crow-bar protection is gradually removed, grid voltage start recovering and results in high reactive power consumption of DFIG(figure 4.8(a)). During this time, the voltage of grid increases leading to less error between reference and measure value of voltage. The reactive power of GSC drops down and when the crow bar is completely removed $(\mathrm{t}=300 \mathrm{~ms})$, GSC goes back to unity power factor mode for normal operation.

\section{CONCLUSIONS AND FUTURE WORKS:}

This paper presented step by step, the optimization of DFIG Wind Turbine controller. Based on the standard model of DFIG, the Fault Controller, Frequency Stabilizer, Drive Train Stabilizer and STATCOM action of Converter are added to improve fault ride through capability of DFIG. Throughout this project, DIgSILENT Power Factory Simulation Program is used to demonstrate and confirm controllers work efficiently. Following issues should be investigated in the future:

- System is assumed operating at full wind speed to be able to investigate the worse stability case happens for WT. More simulation of below rated wind speed is required.

- The stability issue in this paper was limited in local area where the grid is lumped into one big synchronous generator. This generator is left as open loop control and system is dominated by DFIG controller. More investigation about DFIG controller effects on multi-area synchronous generators in larger scale.

- The phase to phase fault requires an adequate study for DFIG Wind Generator. Due to negative sequence power flowing back to machine, the dc link voltage could be experienced in significant voltage fluctuation leading to converter damage.

\section{APPENDIX}

This test case is arranged for a basic model of DFIG wind turbine as in figure 7.1. System parameters are as following:

- Wind turbine: blade radius $\mathrm{R}=50 \mathrm{~m}$, rated wind speed; $v_{\text {rated }}=13.5 \mathrm{~m} / \mathrm{s}$; gear box ratio $n_{\text {gear }}=18$;

-Turbine Damping $D_{t u r}=0 \mathrm{Nms} / \mathrm{rad}$.

- $\quad$ Turbine Inertia $J_{t u r}=6100000 \mathrm{~kg} . \mathrm{mm}$

- $\quad$ Shaft Stiffness $K_{T G}=83000000 \mathrm{Nm} / \mathrm{rad}$

- $\quad$ Torsional Damping $D_{T G}=1400000 \mathrm{Nms} / \mathrm{rad}$

- DFIG: 10x5MW with integration of rotor side converter; $\left(U_{s}\right)_{\text {rated }}=3.3 \mathrm{kV} ;\left(U_{r}\right)_{\text {rated }}=0.69 \mathrm{kV} ; 1$ pole pair.

- $\quad$ Grid side converter: 10x2MVA

- $\quad$ Grid side inductor: 10x2MVA at $0.69 \mathrm{kV}$

- Dc-link capacitor: 10x2MVar at $1.15 \mathrm{kV}$

- Power transformer: 10x6MVA ; 66/3.3/0.69kV; $\left(u_{k}\right)_{H V-M V}=8 \% ;\left(u_{k}\right)_{M V-L V}=\left(u_{k}\right)_{L V-H V}=1 \%$

The Wind Farm PCC $110 \mathrm{kV}$ bus bar is connected to a power system in figure 7.2.

Figure 7.2 demonstrates an area of power system. The rest of system is represented by an Synchronous Generator at PCC $380 \mathrm{kV}$ terminal. New testing system parameters are described as following:

- Lump generator: 615MVA(approximately 10 times wind farm capacity)

Transformer T-1: 380/110kV, 150MVA, $u_{k}=9.5 \%$

Loads:

+BL-ST1: 11MW, 0.86 P.F

+BL-ST2: 35MW, 0.88 P.F

+BL-ST3: $\quad 23.2 \mathrm{MW}, \quad 0.85 \quad$ P.F

+BL-ST4: 25MW, 0.85 P.F

Line: ACSR Al/St $185 / 30 \quad$ type;

$r_{1,2}=0.15 \Omega / \mathrm{km} ; x_{1,2}=0.4 \Omega / \mathrm{km} ; r_{0}=0.31 \Omega / \mathrm{km} ;$

$x_{0}=1.1 \Omega / \mathrm{km}$,

Susceptance $b=2.8 \mu \mathrm{S} / \mathrm{km}$

$l_{L-3-1}=l_{L-3-2}=50 \mathrm{~km}$ 
$l_{L-1-1}=l_{L-1-2}=15 \mathrm{~km}$

$l_{L-2-1}=25 \mathrm{~km}$

Shunt capacitor: $20 \mathrm{MV}$ ar at $110 \mathrm{kV}$

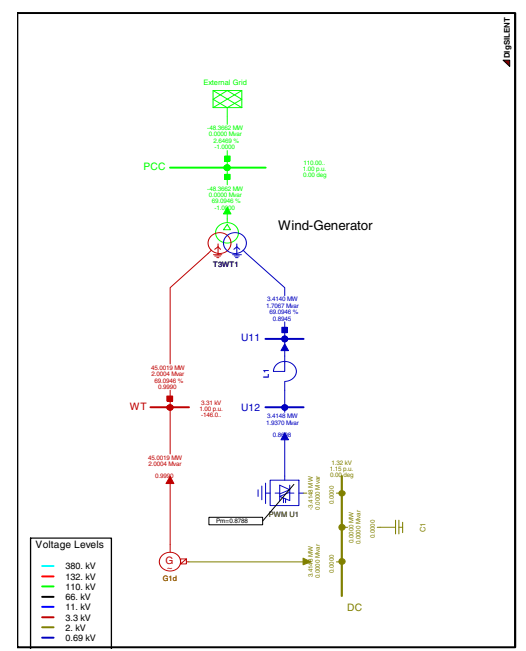

Figure 7.1 DFIG Wind System Model

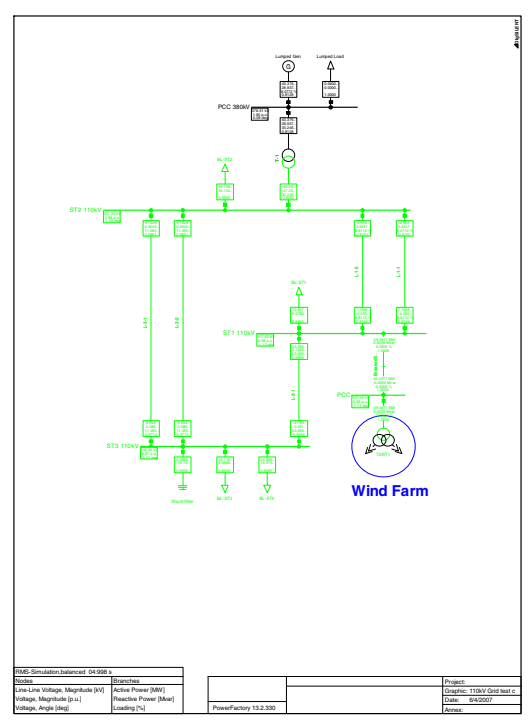

Figure 7.2. Power System Test Case

\section{REFERENCES}

[1] Wind Power in Power System, Ackermann T., Wiley, 2005

[2] Analysis of Dynamic Behavior of Electric Power Systems with Large Amount of Wind Power', PhD thesis, Akhmatov V., Orsted-DTU, Technical University of Denmark, 2003.

[3] Dynamic Modelling of Doubly-Fed Induction Machine Wind-Generators, DIgSILENT GmbH, Gomaringen, Germany, 2003.
[4] 'Specifications for connecting Wind farm to the transmission network-Second edition'. VOL:Doc No74557, ELTRA, 2000, 2002.

[5] Power System Stability and Control, Kundur P., McGraw Hill, New York, 1994.

[6] Power Electronics: Converters, Applications and Design, Mohan N., Undeland, T. M., Robbins, W. P.Clarendon Press, Oxford, UK, 2003.

[7] User Manual DIgSILENT Power Factory 13.0, DIgSILENT GmbH, Gomaringen, Germany, 2003.

\section{BIOGRAPHIES}

Hai Nguyen Dong Le received the B.Eng. degree in electrical engineering from Ho Chi Minh University of Technology, Vietnam, in 2005, M.Eng.Sc in electrical engineering from Curtin University of Technology, Perth, Australia, in 2007. He is currently employed by DIgSILENT Pacific, Perth Australia. His current research interests include power system simulation, stability and protection.

Syed Islam (SM'93) received the B.Sc., M.Sc., and Ph.D. degrees in electrical power engineering from Curtin University of Technology, Perth, Western Australia, in 1979, 1983, and 1988, respectively.

Currently, he is a Professor and Head of the Department of Electrical Engineering at Curtin University of Technology, Perth, Australia. He is also the Deputy Director of the Centre for Renewable Energy and Sustainable Technologies Australia, Perth, and Managing Editor of the International Journal of Renewable Energy Engineering. He has published many research papers in the area of electric power engineering including many in the IEEE. His current research interests include power quality, energy efficiency, and hybrid renewable energy systems.

Dr. Islam is a member of the IEE. He is the recipient of the 1999 IEEE/PES prestigious T. Burke Haye's outstanding Faculty Recognition Award and was the General Chair for the 2006 Australasian Universities Power Engineering (AUPEC) Conference. 